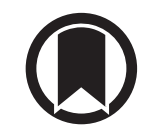

CrossMark

\title{
Estimating the prevalence of latent tuberculosis in a low-incidence setting: Australia
}

\author{
Katie Dorothy Dale ${ }^{1}$, James McCracken Trauer ${ }^{1,2}$, Pete J. Dodd ${ }^{3}$, \\ Rein M.G.J. Houben ${ }^{4,5}$ and Justin Timothy Denholm ${ }^{1,6}$ \\ Affiliations: ${ }^{1}$ Victorian Tuberculosis Program, Melbourne Health, Melbourne, Australia. ${ }^{2}$ School of Public \\ Health and Preventive Medicine, Monash University, Melbourne, Australia. ${ }^{3}$ School of Health and Related \\ Research, University of Sheffield, Sheffield, UK. ${ }^{4}$ TB Modelling Group, TB Centre, London School of Hygiene \\ and Tropical Medicine, London, UK. ${ }^{5}$ Dept of Infectious Disease Epidemiology, London School of Hygiene and \\ Tropical Medicine, London, UK. ${ }^{6}$ Dept of Microbiology and Immunology, The University of Melbourne, \\ Melbourne, Australia.
}

Correspondence: Katie Dorothy Dale, Victorian Tuberculosis Program, Peter Doherty Institute, Level 5, 792 Elizabeth St, Melbourne, VIC 3000, Australia. E-mail: katie.daleamh.org.au

@ERSpublications

Migration is a key driver of tuberculosis (TB) in many low incidence settings. Our method combines global TB infection estimates with migration data to provide useful insights into the prevalence of latent TB in a low-incidence setting, Australia http://ow.ly/gGXM30mma8V

Cite this article as: Dale KD, Trauer JMC, Dodd PJ, et al. Estimating the prevalence of latent tuberculosis in a low-incidence setting: Australia. Eur Respir J 2018; 52: 1801218 [https://doi.org/10.1183/13993003.012182018].

ABSTRACT Migration is a key driver of tuberculosis (TB) in many low-incidence settings, with the majority of TB cases attributed to reactivation of latent TB (LTBI) acquired overseas. A greater understanding of LTBI risk in heterogeneous migrant populations would aid health planning. We aimed to estimate the LTBI prevalence and distribution among locally born and overseas-born Australians.

Annual risks of TB infection estimates were applied to population cohorts (by country of birth, year of arrival and age) in Australian census data in 2006, 2011 and 2016.

Both the absolute number and proportion of Australian residents with LTBI increased from $4.6 \%$ (interquartile range (IQR) 4.2-5.2\%) in 2006 to 5.1\% (IQR 4.7-5.5\%) in 2016, due to the increasing proportion of the population born overseas ( $23.8 \%$ in 2006 to $28.3 \%$ in 2016 ). Of all residents estimated to have LTBI in 2016; $93.2 \%$ were overseas born, $21.6 \%$ were aged $<35$ years and $34.4 \%$ had migrated to Australia since 2007.

The overall prevalence of LTBI in Australia is low. Some residents, particularly migrants from highincidence settings, may have considerably higher risk of LTBI, and these findings allow for tailored public health interventions to reduce the risk and impact of future TB disease. 


\section{Introduction}

In many low-incidence settings, most tuberculosis (TB) cases now occur among residents born in highincidence countries and are attributed to reactivation of latent TB infection (LTBI) acquired overseas [1-3]. LTBI is asymptomatic and not infectious, but those with LTBI can be treated to reduce their future risk of reactivation of TB [4], and several low-incidence countries are now considering, or have implemented, screening and treatment for LTBI among high-risk recent immigrants [5]. It is essential that any strategy is well targeted to those at highest risk of LTBI and active TB to ensure a favourable risk/benefit ratio for both society and individuals $[6,7]$. However, identifying populations at the highest risk can be difficult; migrant populations can be very heterogeneous with regards to source country, age and time since migration, and most LTBI prevalence studies in migrant populations are limited to opportunistically selected groups with identifiable risk factors and demographic profiles that are unlikely to be generalisable to the entire migrant cohort [8].

In 2016, HoubEN and DodD [9] estimated the prevalence of global LTBI by estimating trends in annual risk of infection (ARTI) for 168 countries from 1934 to 2014. In Australia, as in many low-incidence settings, immigration is a key driver of the burden of LTBI and rich data exist on immigration by country of origin, age and year. Therefore, the potential exists to combine estimated TB infection rates with domestic census data to quantify the LTBI burden and understand the effects of immigration.

We aimed to estimate the prevalence of LTBI in Australia, to describe its evolution over time and identify populations at greatest risk of infection. This is an important first step in identifying those populations that are at the highest risk of TB reactivation, and will inform future effective public health interventions towards TB elimination.

\section{Methods}

\section{Australian census data}

Australian population data from the 2006, 2011 and 2016 censuses were exported from the Australian Bureau of Statistics (ABS) TableBuilder [10] by country of birth, age, year of arrival, state/territory of residence and residence within state/territory's capital city.

Residents categorised as "not stated", "inadequately described" or "at sea" in the census country of birth or year of arrival categories were excluded from the analysis [11].

\section{Annual risk of infection}

The methods used by Houben and DodD [9] to construct trends in ARTI for 168 countries from 1934 to 2014 have been described in detail previously. Briefly, for each country and for each year, 200 simulated ARTI trajectories were estimated using data from tuberculin skin test (TST) surveys, with sample size and mean age used to quantify uncertainty. Where TST surveys were unavailable, estimates of ARTI were obtained using a revised Styblo ratio that accounts for uncertainty [12]. The Styblo ratio relates the ARTI and prevalence of smear-positive tuberculosis $[13,14]$. The prevalence of smear-positive TB was estimated using World Health Organization (WHO) Global TB Programme prevalence estimates (1990-2014) [15] and incorporating WHO assumptions regarding case detection rates and disease duration by HIV status, as well as assumptions regarding the fraction of smear-positive disease by HIV status [16] and age group [17].

To increase precision for the six most common countries of birth in Australia (Australia, the United Kingdom, China, Vietnam, India and the Philippines), we simulated 5000 ARTI trajectories. To reflect characteristics relevant to transmission in Australia, the proportion of TB cases that were smear-positive was set to $21.5 \%$ based on the Australian average proportion from 2008 to 2013 [1, 18-20]. The ARTI estimate for 2014 was applied to the years 2015 and 2016, and the estimate for 1934 was applied to all prior years.

The risk of infection for each population cohort (by country of birth, age and year of arrival if overseas-born) in each census dataset was calculated by summing the relevant hazards (force of infection (FOI)) for each year of residency in Australia and birth country (for overseas-born residents). To account for variation in birth dates and dates of migration across years (which were unknown), the hazards in birth years were halved, and in years of migration half the hazard for each of the birth country and Australia was used. This assumes that the average time of birth or migration of the cohort was the mid-point of the year of birth or migration. Hazards in census years were apportioned based on the census date. The total risk of infection $(\mathrm{R})$ for each population group was then calculated as one minus the exponential of the cumulative FOIs experienced:

$$
R=1-e^{\sum-(A l l F O I s)} \text { where FOI }=\text { force of infection }
$$


A full mathematical description of this method is presented in the online supplementary material. Data are presented as median (interquartile range (IQR)).

\section{Ethics statement}

Approval from a human research ethics committee was not required under the rules of our institutions.

\section{Results}

\section{LTBI in Australia}

The number of Australians estimated to have LTBI increased over time from 838000 (IQR 764000-950 000) in 2006 to 1084000 (IQR 1017000-1 172000) in 2016, with the percentage of Australians estimated to have LTBI increasing from 4.6\% (IQR 4.2-5.2\%) in 2006 to $5.1 \%$ (IQR 4.7-5.5\%) in 2016 (figure 1). Our results are estimates based on a Bayesian approach, and so computing p-values for comparisons between years was not appropriate, but the uncertainty intervals suggest no strong evidence of a trend.

Considering the Australian-born and overseas-born groups separately, the estimated LTBI percentages in the Australian-born residents were comparable in 2006 and $2016(0.4 \%$, IQR $0.3-0.9 \%$ and $0.4 \%$, IQR $0.3-0.7 \%)$ and the percentage of overseas-born residents infected also changed little, from $18.0 \%$ (IQR $16.7-19.6 \%$ ) to $17.1 \%$ (IQR $16.2-18.1 \%$ ). The reason why the proportions in the Australian-born and overseas-born subgroups changed little over time while there was a simultaneous increase in the proportion of all Australians estimated to have LTBI was because of the increasing proportion of the
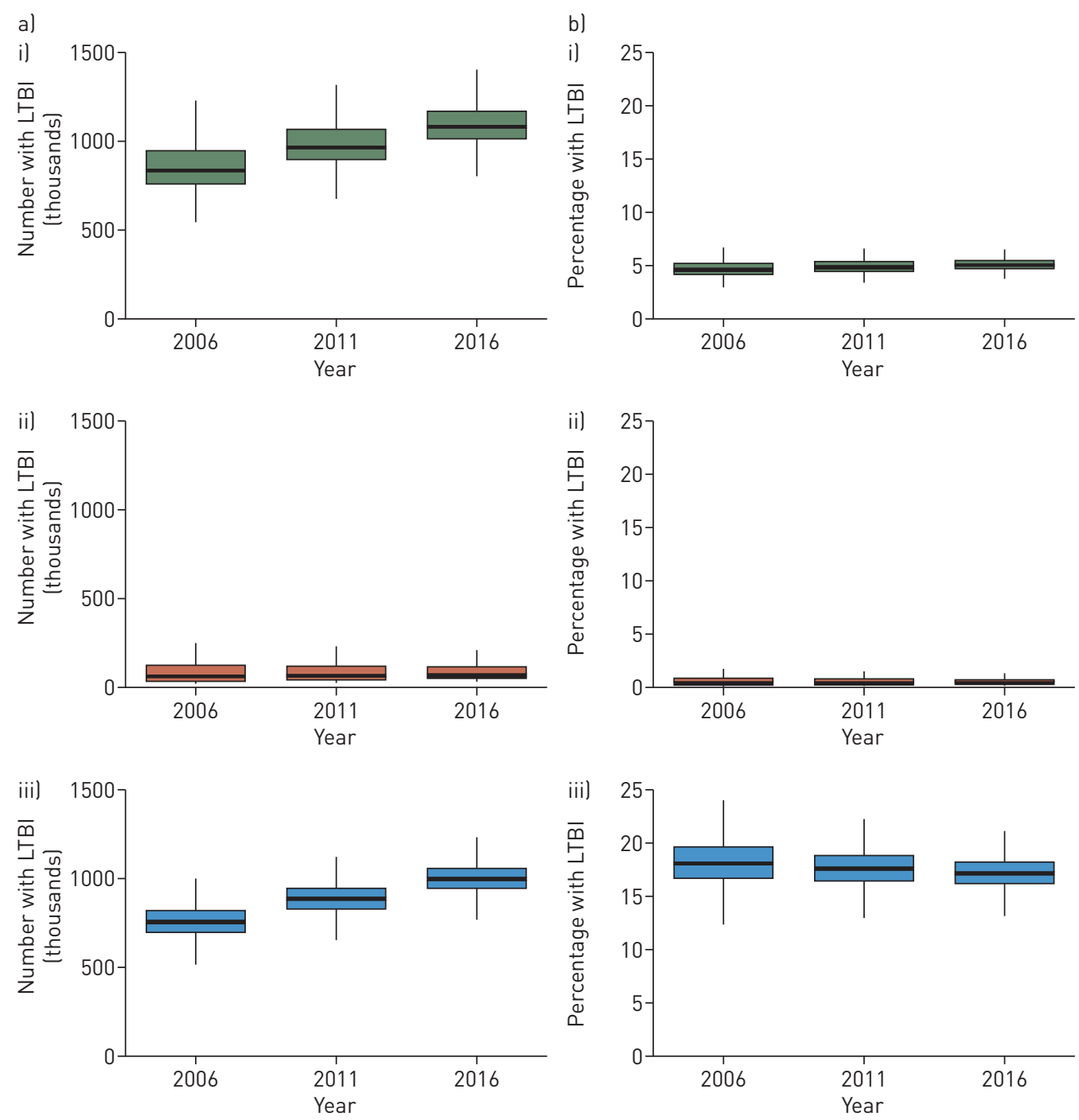

FIGURE 1 a) Number and b) percentage of Australians estimated to have latent tuberculosis infection (LTBI) by census year. i) All residents; ii) Australian-born residents; iii) overseas-born resisdents. Vertical lines represent data points that are no more than 1.5 times the interquartile range from the box. 
Australian population who were born overseas during the study years ( $23.8 \%$ in 2006 to $28.3 \%$ in 2016 ). The number of overseas-born residents estimated to have LTBI increased from 756000 (IQR 699000-822 000) in 2006 to 998000 (IQR $943000-1058000$ ) in 2016.

With declining ARTI estimates in many countries worldwide, the percentage estimated to have LTBI increased with age in both Australian-born and overseas-born populations (figure 2). Due to the age distribution of the populations (not shown), the largest number estimated to have LTBI were in the 35-64-year age groups (figure 2).

Among overseas-born residents, the number of persons with LTBI increased between 2006 and 2016 in all age groups, with the largest absolute increase in the 35-64-year and 15-34-year age groups, and percentage increases of $37.7 \%, 69.4 \%, 25.4 \%$ and $26.6 \%$ in the $0-14,15-34,35-64$ and $\geqslant 65$-year age groups, respectively (figure 2). The proportion of overseas-born residents estimated to have LTBI appeared to decrease marginally over time in all age groups, except in the 35-64-year group, in which it changed little from 19.5\% (IQR 17.9-21.1\%) in 2006 to $20.1 \%$ (IQR 18.7-21.3\%) in 2016 (figure 2).

The average age of residents with LTBI appeared to decrease slightly from 51.9 years in 2006 to 50.7 years in 2016, increasing in the Australian-born population (50.5 years in 2006 to 52.4 years in 2016) and decreasing in the overseas-born population ( 52.0 years in 2006 to 50.6 years in 2016). The percentage of residents with LTBI aged <35 years increased from $17.4 \%$ in 2006 to $21.6 \%$ in 2016 .

\section{Overseas-born residents}

In 2016, >6.1 million Australian residents were born overseas in $>190$ countries, constituting $28.3 \%$ of the Australian population. The increasing numbers of Australians born in high-burden countries [21] over time is illustrated in figure 3. Australian residents born in India, China, the Philippines and Vietnam made up the greatest number estimated to have LTBI in 2016; with the prevalence varying by age (table 1 and figure 4).

\section{Overseas-born residents arriving 2007-2016}

An estimated 15.4\% of migrants arriving between 2007 and the census in 2016 had LTBI on arrival, with this group contributing $34.4 \%$ of all LTBI in Australia in 2016, and new migrants aged <35 years contributing $16.3 \%$.
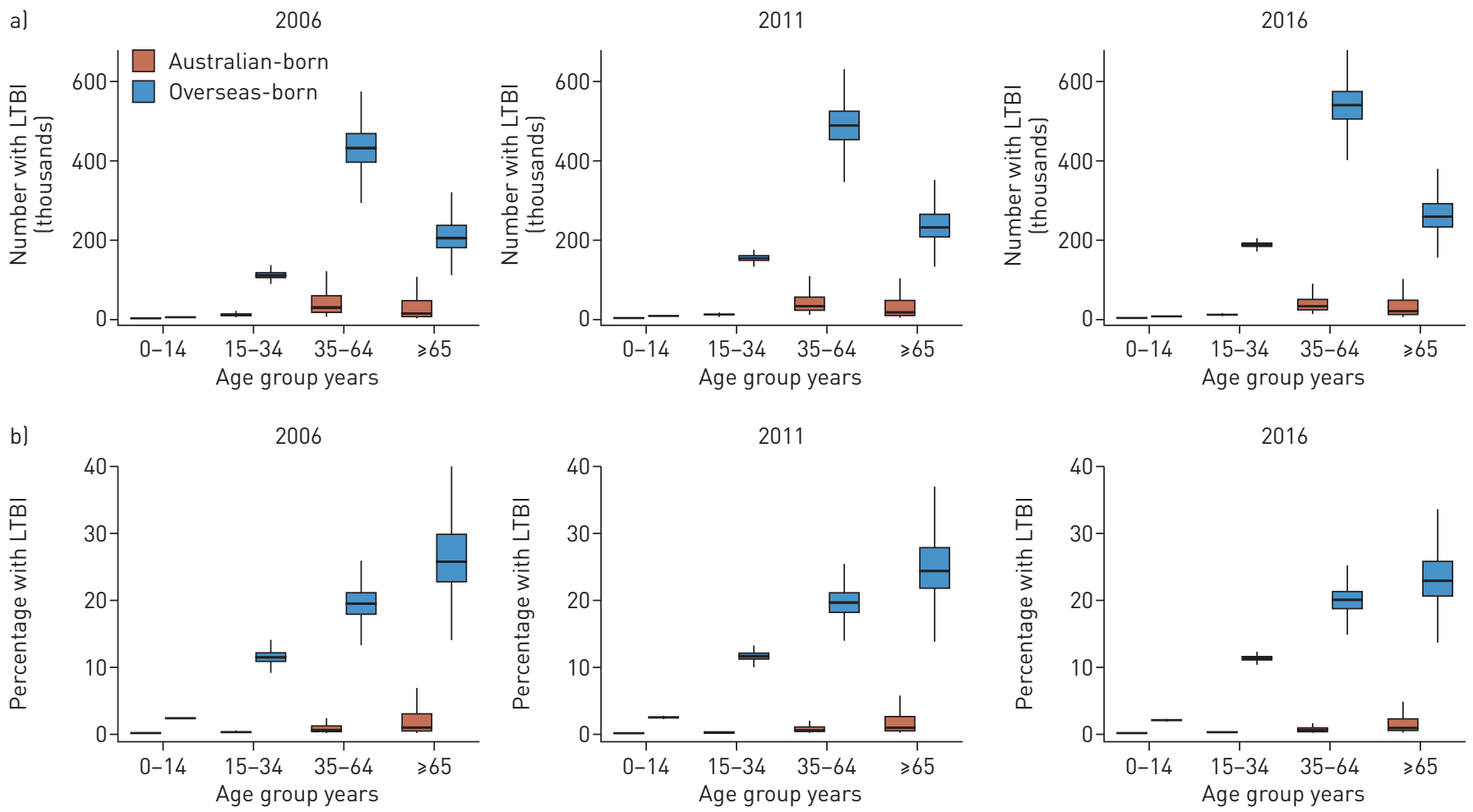

FIGURE 2 Estimated al number and b) percentage estimated to have latent tuberculosis infection (LTBI) by age group and census year. Vertical lines represent data points that are no more than 1.5 times the interquartile range from the box. 
a)

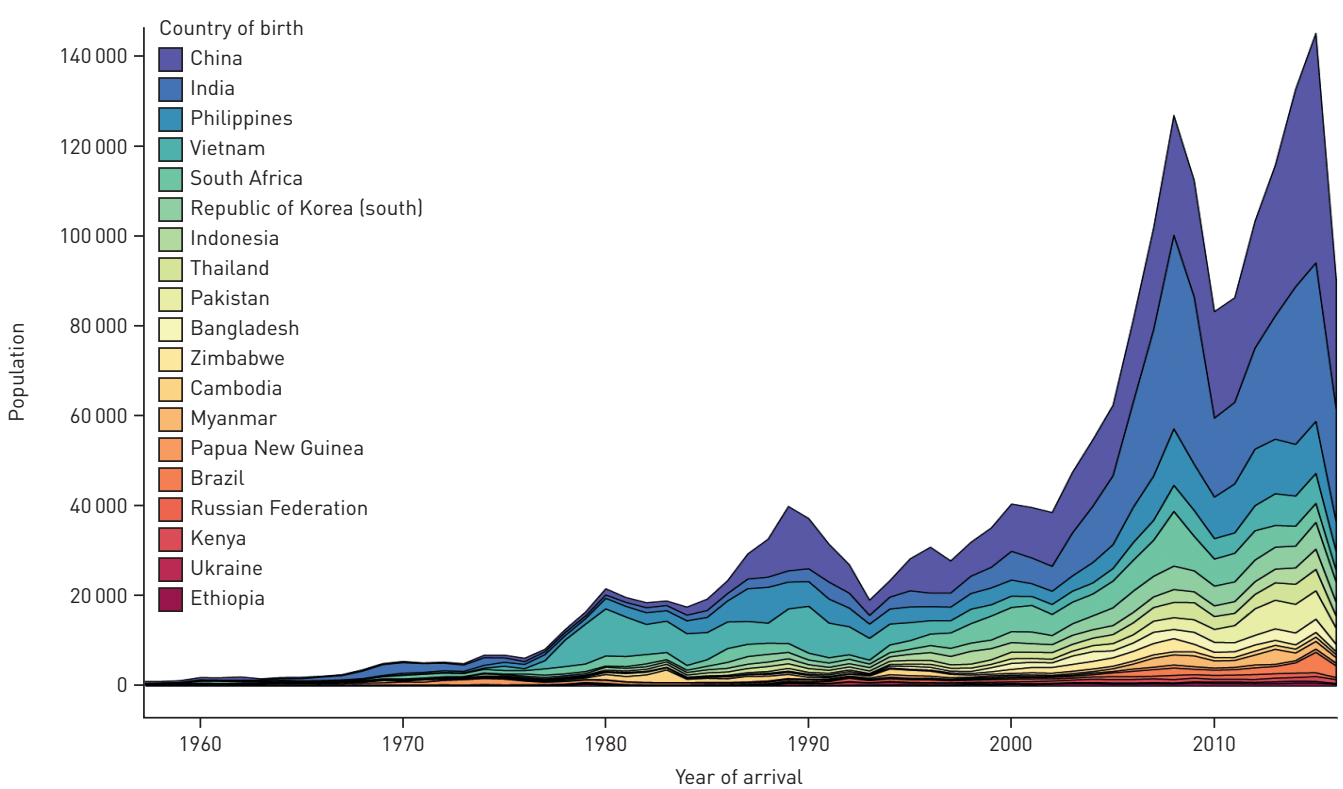

FIGURE 3 Number arriving by year of Australian residents in 2016 who were born in countries with a high burden of tuberculosis (TB) las defined by the World Health Organization 2017 Global TB Report [21]). Countries of birth with $<10000$ residents were excluded.

\section{Spatial distribution}

The majority of persons with LTBI resided in major urban centres, particularly Greater Sydney and Greater Melbourne (online supplementary figure S1). LTBI prevalence increased in all regions from 2006 to 2016 , most notably in the Northern Territory (1.7\% in 2006 to 3.3\% in 2016) and Greater Perth (3.8\% to $4.9 \%)$. The distribution of risk within smaller geographical areas can also be examined, where census data provide this level of spatial detail (online supplementary figure S1).

\section{Missing data}

The percentages missing country of birth and/or year of arrival information in the 2006, 2011 and 2016 census data were $8.0 \%, 6.7 \%$ and $9.15 \%$, respectively. These census respondents were largely categorised as "not stated" and for a significant percentage ( $70-80 \%$ depending on the year) the answers to most other census questions were similarly "not stated", suggesting that they had been imputed by the ABS to account for nonresponding dwellings [11, 22, 23]. The ABS post-enumeration survey data in the census years estimated the majority of nonresponders to be Australian-born (e.g. 84.8\% in 2016, which was calculated using the Tablebuilder census count and published net undercount rate of $8.1 \%)[11,22,23]$, and countries of birth of other nonresponders were similarly distributed to census respondents in 2016.

\section{Discussion}

Our method provided useful insights into the prevalence of LTBI in Australia; a low-incidence setting with high levels of migration. Both the prevalence and total number of people with LTBI in Australia rose from 2006 to 2016, with the highest proportions seen in major metropolitan areas. The increasing prevalence of LTBI can be attributed to increasing numbers of overseas-born residents from countries with a high burden of TB, such as India, China and the Philippines. New arrivals were predominantly young adults and families, such that an increasing proportion of those estimated to have LTBI during the study period were aged $<35$ years. During this time, we found that $\sim 15 \%$ of migrants to Australia had LTBI. However, due to high levels of migration from high-burden countries since the 1980s, the majority of those estimated to have LTBI in Australia in 2016 were aged $>35$ years.

Our study highlighted that despite the increasing prevalence of LTBI in Australia, the prevalence is low (5.1\% in 2016) and far lower than the estimated global burden of $23 \%$ in 2014 [9]. Moreover, the proportion of residents estimated to have LTBI in the overseas-born population appeared to fall over time, due to the declining incidence of TB in the countries where most overseas-born residents were born (for example, India and China) [21]. How the prevalence of LTBI in Australia, and other similar low-incidence 
TABLE 1 Estimated latent tuberculosis infection (LTBI) among Australian residents in 2016, with country-specific results from the 10 countries of birth contributing the greatest numbers with LTBI

\begin{tabular}{|c|c|c|c|c|c|c|c|c|c|c|}
\hline & \multirow{2}{*}{$\begin{array}{l}\text { Percentage of } \\
\text { Australian } \\
\text { population }\end{array}$} & \multirow{2}{*}{$\begin{array}{c}\text { Number of residents } \\
\text { with LTBI } \\
\text { (thousands) }\end{array}$} & \multirow{2}{*}{$\begin{array}{c}\text { Age of } \\
\text { resident } \\
\text { with LTBI } \\
\text { (years) }\end{array}$} & \multirow{2}{*}{$\begin{array}{l}\text { Time since arrival } \\
\text { of those estimated } \\
\text { to have LTBI } \\
\text { (years) }\end{array}$} & \multirow{2}{*}{$\begin{array}{l}\text { Percentage of } \\
\text { all LTBI in } \\
\text { Australia }\end{array}$} & \multicolumn{5}{|c|}{ Percentage with LTBI by age group } \\
\hline & & & & & & $0-14$ years & $15-34$ years & $35-64$ years & $\geqslant 65$ years & All \\
\hline China & 2.3 & $113(89-140)$ & 53 & 12 & 11.8 & $1.5(1.4-1.6)$ & $9.1(8.5-9.8)$ & $29.2(22.3-38.4)$ & $65.6(43.2-85.8)$ & $21.3(16.8-26.6)$ \\
\hline India & 2.1 & $115(108-124)$ & 36 & 8 & 12.1 & $2.9(2.7-3.1)$ & $22.9(21.6-24.3)$ & $31.5(29.3-34.5)$ & $45.9(38.2-54.9)$ & $26.0(24.4-28.0)$ \\
\hline Philippines & 1.1 & $101(85-117)$ & 47 & 12 & 10.6 & $6.8(6.3-7.3)$ & $28.1(26.5-30.0)$ & $55.3(45.8-66.1)$ & $80.2(57.4-96.0)$ & $44.7(37.9-51.8$ \\
\hline Vietnam & 1.0 & $96(61-125)$ & 55 & 27 & 10.0 & $3.3(3.0-3.6)$ & $18.9(17.0-21.4)$ & $49.9(29.8-70.0)$ & $91.0(57.8-99.9)$ & $45.5(29.1-59.5$ \\
\hline South Africa & 0.7 & $37(30-52)$ & 45 & 9 & 3.8 & $8.2(7.6-9.0)$ & $16.8(15.9-18.3)$ & $27.4(21.5-39.1)$ & $25.8(16.1-56.9)$ & $22.9(18.6-32.4)$ \\
\hline Indonesia & 0.3 & $32(30-33)$ & 41 & 13 & 3.3 & $7.9(7.4-8.4)$ & $34.4(33.1-35.6)$ & $53.1(50.9-55.5)$ & $67.5(56.4-79.7)$ & $44.6(42.7-46.6)$ \\
\hline Cambodia & 0.2 & $24(20-26)$ & 49 & 25 & 2.6 & $11.5(10.8-12.2)$ & $50.0(46.2-54.6)$ & $85.6(66.0-93.3)$ & $100.0(91.4-100.0)$ & $76.0(62.6-82.0)$ \\
\hline South Korea & 0.5 & $25(23-27)$ & 49 & 14 & 2.6 & $1.4(1.3-1.6)$ & $9.1(8.5-9.9)$ & $39.6(36.0-43.2)$ & 92.6 (84.9-97.8) & 26.7 \\
\hline Pakistan & 0.3 & $17(15-18)$ & 35 & 5 & 1.8 & $4.1(3.8-4.4)$ & $24.2(23.0-25.6)$ & $41.5(36.0-48.5)$ & $68.7(54.3-79.6)$ & $27.9(25.4-30.9)$ \\
\hline Myanmar & 0.2 & $16(13-18)$ & 45 & 8 & 1.7 & $9.4(8.5-10.2)$ & $34.3(32.0-36.6)$ & $60.4(49.4-75.7)$ & $87.3(61.2-98.4)$ & $51.1(42.6-59.1)$ \\
\hline Other countries & 19.6 & $413(378-456)$ & 56 & 25 & 39.8 & $0.9(0.9-1.0)$ & $5.4(5.3-5.6)$ & $10.4(9.7-11.2)$ & $16.8(14.6-20.1)$ & $10.4(9.5-11.4)$ \\
\hline $\begin{array}{l}\text { All overseas-born } \\
\text { residents }\end{array}$ & 28.3 & 998 (943-1058) & 49 & 15 & 93.2 & $2.1(2.0-2.1)$ & $11.3(11.1-11.6)$ & $20.1(18.7-21.3)$ & $22.9(20.6-25.8)$ & $17.1(16.2-18.1$ \\
\hline $\begin{array}{l}\text { Australian-born } \\
\text { residents }\end{array}$ & 71.7 & $65(48-112)$ & 54 & & 6.8 & $0.1(0.1-0.1)$ & $0.3(0.2-0.3)$ & $0.6(0.4-0.9)$ & $0.9(0.5-2.3)$ & $0.4(0.3-0.7)$ \\
\hline
\end{tabular}


a)
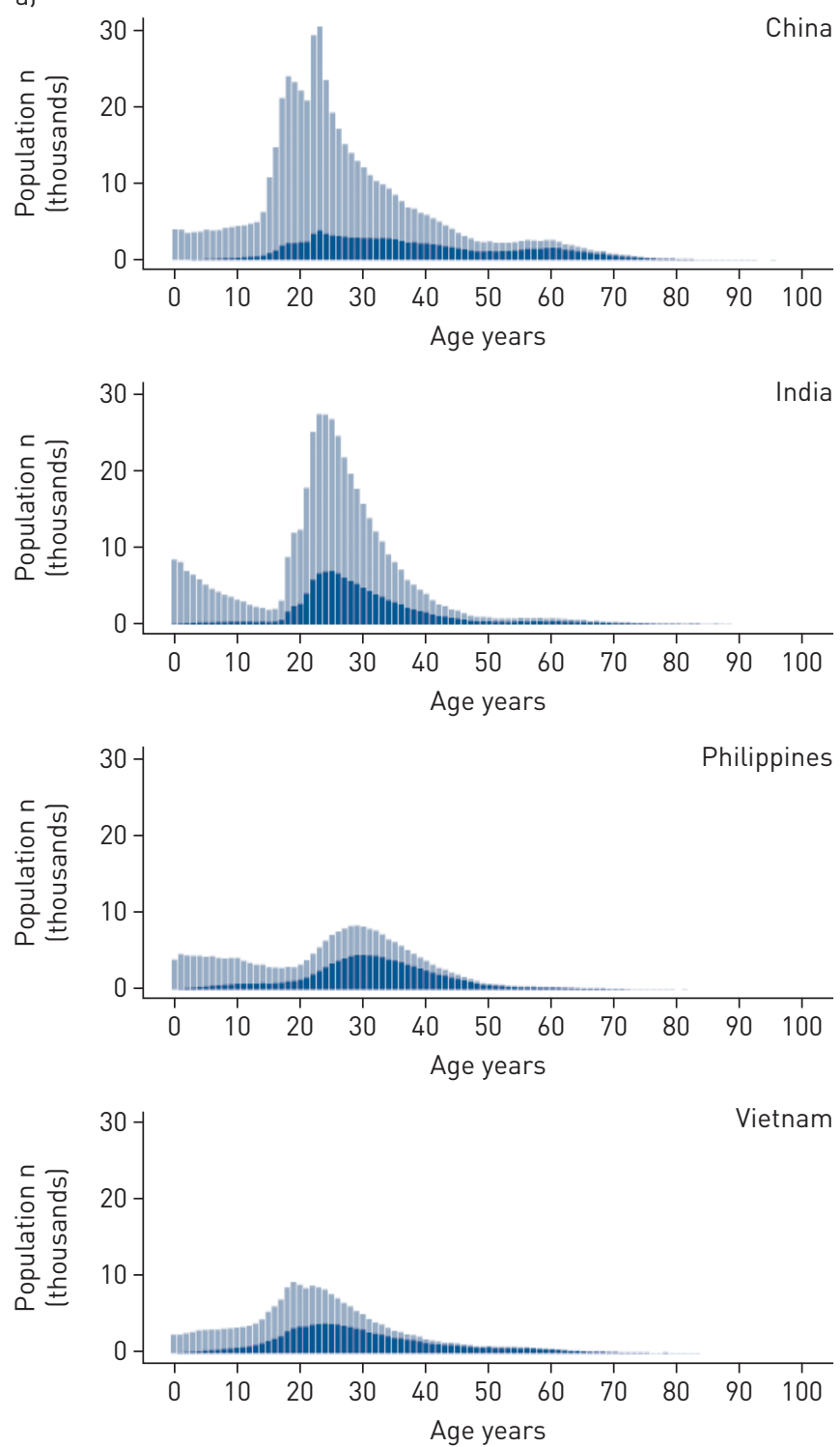

b)
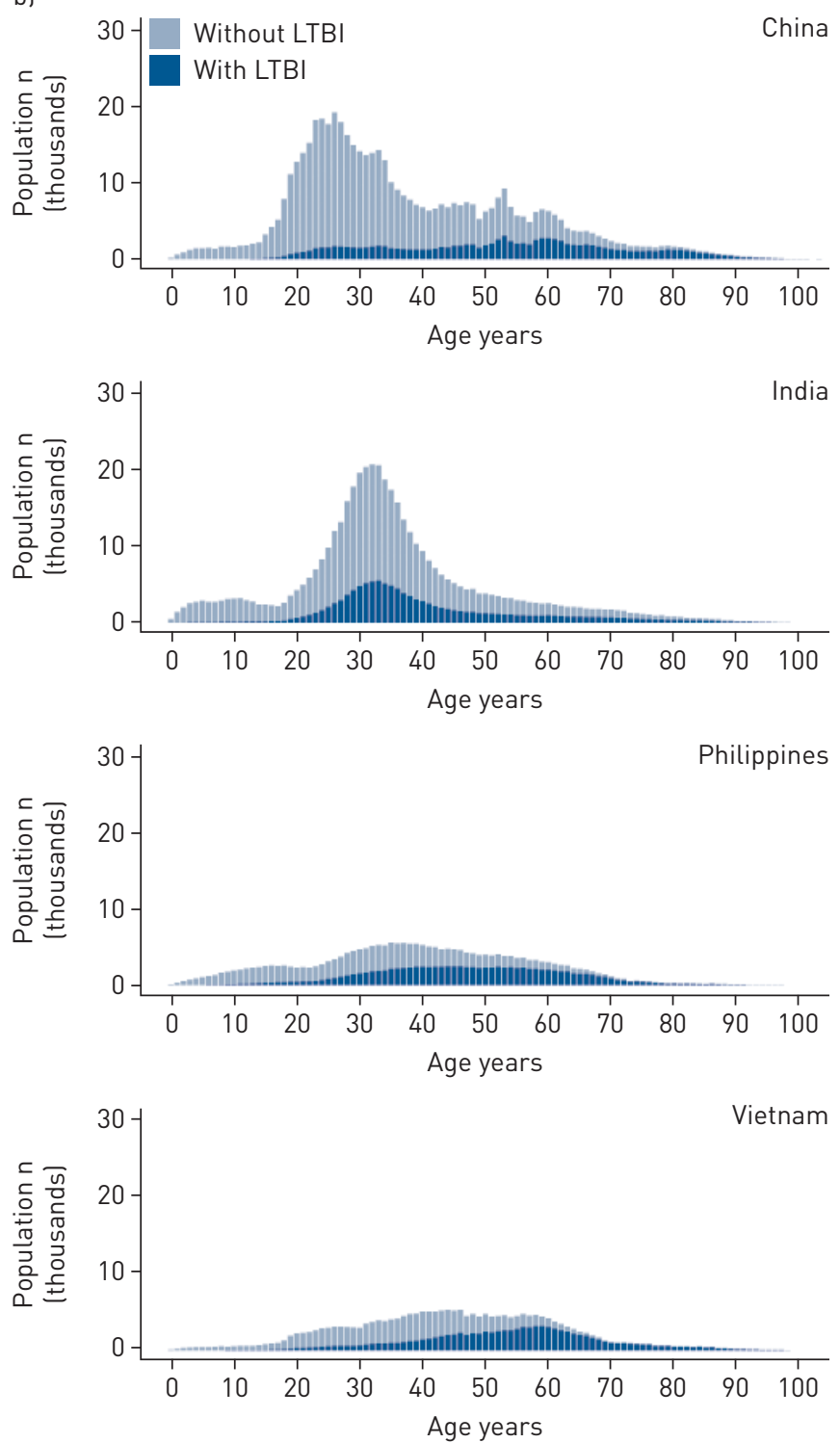

FIGURE 4 Estimated number of overseas-born residents in Australia for the four most common countries of birth, by age and latent tuberculosis infection (LTBI) status, at a) time of migration and b) the 2016 census.

settings changes in the future will be influenced by rates of migration, age at migration, source countries and how TB incidence in those source countries changes over time, in addition to the implementation and effectiveness of any additional TB control strategies locally.

Looking to the future, the addition of LTBI screening and treatment could be considered for migrant groups in Australia, as is done in several other low-incidence countries [24]. LTBI treatment is commonly limited to those aged $<35$ years because the frequency of adverse effects increases with age $[25,26]$, although recent research has shown that shorter LTBI treatment regimens containing rifampicin have a significantly lower risk of hepatotoxicity, so recommendations for testing older age groups may expand in future [27]. Our approach is able to quantify LTBI burden in subpopulations from low-burden countries, ensuring improved estimates of the pre-test probability of LTBI essential for predicting the efficiency of any proposed screening programme. In addition, understanding LTBI distribution is helpful even where preventive therapy would not be indicated, and allows alternative interventions (such as community and healthcare worker education about TB disease) to be optimised. Migrants arriving from high-burden settings from 2007 to 2016 made up $>30 \%$ of all those with LTBI in Australia in 2016, and because recently arriving migrants are at higher risk of reactivating than those who have settled in Australia for longer [28], screening and treating this group may be beneficial. 
Quantifying this benefit will be a focus of future work, which will incorporate estimation of TB reactivation rates among subpopulations with LTBI. Given the significant uncertainty around rates of LTBI reactivation [29] this work will be beneficial in predicting the benefit of screening and treatment strategies in our setting.

In low-incidence settings, where national TST prevalence surveys have long been abandoned and the majority of cases occur among overseas-born residents, indirect LTBI estimates based on modelled annual risks of infection in countries of birth combined with migration data are a natural approach. Our analysis incorporates both TB incidence in countries of birth and age, both of which have been shown to be independently associated with the prevalence of LTBI among migrants in the international literature $[8,30,31]$. Limitations of our approach include applying a constant ARTI for all residents of a particular country in a particular year, which obscures individual variation in risk within populations due to a range of risk factors, such as immunological status [32].

Migrants who move from a high TB-burden setting to a low-incidence setting may do so for many different reasons and may not be representative (demographically or socioeconomically) of individuals of the same age in their country of origin [33], which may influence their risk of having been infected. Most LTBI prevalence studies, including those in Australia [34-36], exclusively consider refugee populations; which are often screened due to a perception of higher risk [37]. Previously published LTBI prevalence in these populations do exceed our estimates (data not shown) [34-36]; however, humanitarian entrants made up only $2-3 \%$ of all migrants to Australia in 2006-2016, and we consider this unlikely to substantially impact our estimates presented here [38]. Furthermore, we note that several international studies in migrant cohorts have resulted in similar estimates to those using our method. LTBI prevalence estimates in the entire US migrant population were provided by SHEA et al. [39] using results from the 1999-2000 National Health and Nutrition Examination Survey, and they reported that $18.7 \%$ of overseas-born residents had LTBI. In comparison, our method leads to an estimated prevalence of $18.0 \%$ in overseas-born Australians in 2006. A separate UK study among all migrants attending three UK medical centres (2008-2010) found that $144(20 \%)$ out of 740 born in the Indian subcontinent (aged $\leqslant 35$ years) were interferon- $\gamma$ release assay-positive [8], and in equivalent subsets from Australian migration data in 2006 (by country of birth, year of arrival and age), we estimated $20.9 \%$ to have LTBI. Overall, our estimates appear concordant with existing data from testing in migrant populations.

Additionally, some uncertainty must be acknowledged due to the small amount of missing census data. Despite this, census data remain a good source of comprehensive data, and post-enumeration survey data suggested that the countries of birth of census nonrespondents did not differ greatly from the census respondents [11], meaning that although we have probably slightly underestimated the numbers with LTBI, the proportions presented should be less affected.

In addition, our method made the assumption that, once infected, individuals remained infected for life, and so provides information about the risk of an individual having ever been infected. No allowance was made for the possibility that individuals may clear LTBI over time since infection, for which there is evidence [40, 41]. Furthermore, in some settings LTBI screening and treatment may already be systematically provided to certain migrant groups and LTBI estimates may need to account for this. This is not the case in Australia, where overseas visa applicants identified as having old, inactive TB upon chest radiography may be offered LTBI screening and treatment as part of their health follow-up [42]; however, the impact of these practices on overall LTBI prevalence is likely to be small, due to the small number of migrants referred to the programme [43].

Our method combines global TB infection estimates with migration data to provide useful insights into the prevalence of latent TB in our low-incidence setting. The method could be easily repeated in any setting with reliable census data. Resulting quantitative estimates can assist in developing rational strategies for LTBI screening, which allow for opportunities to promote the long-term health of overseas-born residents and contribute towards the ultimate goal of global TB elimination.

Author contributions: K.D. Dale conceived the study, performed data preparation, analysis and wrote the article. R.M.G. J. Houben and P.J. Dodd developed the annual risk of infection estimates and assisted in data analysis. J.T. Denholm and J.M. Trauer assisted in data analysis. All authors contributed to article revisions.

Conflict of interest: None declared.

Support statement: The Miller Foundation funded the Miller Foundation Scholarship for Infection and Immunity, granted to K.D. Dale towards her doctoral studies. P.J. Dodd acknowledges support from the UK Medical Research Council (MR/P022081/1). J.M. Trauer is a recipient of an Early Career Fellowship from the National Health and Medical Research Council. Funding information for this article has been deposited with the Crossref Funder Registry. 


\section{References}

1 Toms C, Stapledon R, Waring J, et al. Tuberculosis notifications in Australia, 2012 and 2013. Commun Dis Intell Q Rep 2015; 39: E217-E235.

2 Dahle UR, Sandven P, Heldal E, et al. Continued low rates of transmission of Mycobacterium tuberculosis in Norway. J Clin Microbiol 2003; 41: 2968-2973.

3 Vanhomwegen J, Kwara A, Martin M, et al. Impact of immigration on the molecular epidemiology of tuberculosis in Rhode Island. J Clin Microbiol 2011; 49: 834-844.

4 Lobue P, Menzies D. Treatment of latent tuberculosis infection: an update. Respirology 2010; 15: 603-622.

5 Kunst H, Burman M, Arnesen TM, et al. Tuberculosis and latent tuberculous infection screening of migrants in Europe: comparative analysis of policies, surveillance systems and results. Int J Tuberc Lung Dis 2017; 21: 840-851.

6 World Health Organization (WHO). Towards TB Elimination: an Action Framework for Low-Incidence Countries. Geneva, WHO, 2014.

7 Denholm JT, Matteelli A, Reis A. In reply. Promoting ethical and evidence-based policies for latent tuberculosis. Int J Tuberc Lung Dis 2015; 19: 1258-1259.

8 Pareek M, Watson JP, Ormerod LP, et al. Screening of immigrants in the UK for imported latent tuberculosis: a multicentre cohort study and cost-effectiveness analysis. Lancet Infect Dis 2011; 11: 435-444.

9 Houben RM, Dodd PJ. The global burden of latent tuberculosis infection: a re-estimation using mathematical modelling. PLoS Med 2016; 13: e1002152.

10 Australian Bureau of Statistics. TableBuilder: Australian Bureau of Statistics, 2017. www.abs.gov.au/websitedbs/ censushome.nsf/home/tablebuilder Date last accessed: July 12, 2017. Date last updated: June 16, 2017.

11 Harding S, Jackson Pulver L, McDonald P, et al. Report on the Quality of 2016 Census Data. Census Independent Assurance Panel to the Australian Statistician. 2017. Available from: www.abs.gov.au/websitedbs/d3310114.nsf/ Home/Independent+Assurance+Panel

12 Dodd PJ, Gardiner E, Coghlan R, et al. Burden of childhood tuberculosis in 22 high-burden countries: a mathematical modelling study. Lancet Glob Health 2014; 2: e453-e459.

13 Styblo K. The relationship between the risk of tuberculosis infection and the risk of developing infectious tuberculosis. Bull Int Union Tuberc Lung Dis 1985; 60: 117-119.

14 Van Leth F, Van der Werf M, Borgdorff M. Prevalence of tuberculous infection and incidence of tuberculosis: a re-assessment of the Styblo rule. Bull World Health Organ 2008; 86: 20-26.

15 World Health Organization (WHO). Global Tuberculosis Report 2015. Geneva, WHO, 2015.

16 Corbett E, Watt C, Walker N, et al. The growing burden of tuberculosis: global trends and interactions with the HIV epidemic. Arch Intern Med 2003; 163: 1009-1021.

17 Kunkel A, Abel Zur Wiesch P, Nathavitharana RR, et al. Smear positivity in paediatric and adult tuberculosis: systematic review and meta-analysis. BMC Infect Dis 2016; 16: 282.

18 Bareja C, Waring J, Stapledon R, et al. Tuberculosis notifications in Australia, 2011. Commun Dis Intell Q Rep 2014; 38: E356-E368.

19 Bareja C, Waring J, Stapledon R. Tuberculosis notifcations in Australia, 2010. Commun Dis Intell Q Rep 2014; 38: E36-E48.

20 Barry C, Waring J, Stapledon R, et al. Tuberculosis notifications in Australia, 2008 and 2009. Commun Dis Intell Q Rep 2012; 36: 82-94.

21 World Health Organization (WHO). Global Tuberculosis Report 2017. Geneva, WHO, 2017.

22 Australian Bureau of Statistics (ABS). 2940.0 - Census of Population and Housing - Details of Undercount, Australia. Canberra, ABS, 2012.

23 Australian Bureau of Statistics (ABS). 2940.0 - Census of Population and Housing - Details of Undercount Canberra, ABS, 2007.

24 Pareek M, Baussano I, Abubakar I, et al. Evaluation of immigrant tuberculosis screening in industrialized countries. Emerging Infect Dis 2012; 18: 1422-1429.

25 Fountain FF, Tolley E, Chrisman CR, et al. Isoniazid hepatotoxicity associated with treatment of latent tuberculosis infection: a 7-year evaluation from a public health tuberculosis clinic. Chest 2005; 128: 116-123.

26 Saukkonen JJ, Cohn DL, Jasmer RM, et al. An official ATS statement: hepatotoxicity of antituberculosis therapy. Am J Respir Crit Care Med 2006; 174: 935-952.

27 Menzies D, Adjobimey M, Ruslami R, et al. Four months of rifampin or nine months of isoniazid for latent tuberculosis in adults. $N$ Engl J Med 2018; 379: 440-453.

28 McBryde ES, Denholm JT. Risk of active tuberculosis in immigrants: effects of age, region of origin and time since arrival in a low-exposure setting. Med J Aust 2012; 197: 458-461.

29 Esmail H, Barry CE 3rd, Young DB, et al. The ongoing challenge of latent tuberculosis. Philos Trans R Soc Lond B Biol Sci 2014; 369: 20130437.

30 Pareek M, Bond M, Shorey J, et al. Community-based evaluation of immigrant tuberculosis screening using interferon $\gamma$ release assays and tuberculin skin testing: observational study and economic analysis. Thorax 2013; 68: 230-239.

31 Campbell JR, Sasitharan T, Marra F. A systematic review of studies evaluating the cost utility of screening high-risk populations for latent tuberculosis infection. Appl Health Econ Health Policy 2015; 13: 325-340.

32 Styblo K. Epidemiology of Tuberculosis. Royal Netherlands Tuberculosis Association Selected Papers. The Hague, Royal Netherlands Tuberculosis Association, 1991.

33 Pareek M, Greenaway C, Noori T, et al. The impact of migration on tuberculosis epidemiology and control in high-income countries: a review. BMC Med 2016; 14: 48.

34 Martin JA, Mak DB. Changing faces: a review of infectious disease screening of refugees by the Migrant Health Unit, Western Australia in 2003 and 2004. Med J Aust 2006; 185: 607-610.

35 Tiong AC, Patel MS, Gardiner J, et al. Health issues in newly arrived African refugees attending general practice clinics in Melbourne. Med J Aust 2006; 185: 602-606.

36 Gibney KB, Mihrshahi S, Torresi J, et al. The profile of health problems in African immigrants attending an infectious disease unit in Melbourne, Australia. Am J Trop Med Hyg 2009; 80: 805-811.

37 Barnett ED. Infectious disease screening for refugees resettled in the United States. Clin Infect Dis 2004; 39: 833-841. 
38 Phillips J, Simon-Davies J. Migration to Australia: a Quick Guide to the Statistics. Research Paper Series, 2016-17. Department of Parliamentary Services, Parliament of Australia, 2017.

39 Shea KM, Kammerer JS, Winston CA, et al. Estimated rate of reactivation of latent tuberculosis infection in the United States, overall and by population subgroup. Am J Epidemiol 2014; 179: 216-225.

40 Winqvist N, Björk J, Miörner H, et al. Long-term course of Mycobacterium tuberculosis infection in Swedish birth cohorts during the twentieth century. Int J Tuberc Lung Dis 2011; 15: 736-740.

41 Wiker HG, Mustafa T, Bjune GA, et al. Evidence for waning of latency in a cohort study of tuberculosis. BMC Infect Dis 2010; 10: 37.

42 Department of Health \& Human Services. Management, Control and Prevention of Tuberculosis Guidelines for Health Care Providers, 2015. Available from: www.thermh.org.au/sites/default/files/media/documents/Management \%2C\%20control\%20and\%20prevention\%20 of \%20tuberculosis\%20-\%20Guidelines\%20for\%20health\%20care\%20prov iders\%20-\%202015.pdf

43 Flynn MG, Brown LK. Treatment of latent tuberculosis in migrants to Victoria. Commun Dis Intell Q Rep 2015; 39: E578-E583. 